\title{
Magnetic resonance measurement of fluid dynamics and transport in tube flow of a near-critical fluid
}

\section{Authors: Joshua M. Bray, Erik M. Rassi, Joseph D. Seymour, \& Sarah L. Codd}

NOTICE: The final publication is available at Springer via http://dx.doi.org/10.1007/ s00348-014-1777-6.

Bray JM, Rassi EM, Seymour JD, Codd SL, "Magnetic resonance measurement of fluid dynamics and transport in tube flow of a near-critical fluid," Exp Fluids, 2014 55(7):1777 


\title{
Magnetic resonance measurement of fluid dynamics and transport in tube flow of a near-critical fluid
}

\author{
Joshua M. Bray • Erik M. Rassi • Joseph D. Seymour • Sarah L. Codd \\ J. M. Bray · E. M. Rassi · S. L. Codd \\ Mechanical and Industrial Engineering Department, Montana State University, 314 Roberts Hall, Bozeman, MT 59717, USA \\ J. M. Bray · J. D. Seymour \\ Department of Chemical and Biological Engineering, Montana State University, Bozeman, MT, USA
}

\begin{abstract}
An ability to predict fluid dynamics and trans-port in supercritical fluids is essential for optimization of applications such as carbon sequestration, enhanced oil recovery, "green" solvents, and supercritical coolant sys-tems. While much has been done to model supercritical velocity distributions, experimental characterization is sparse, owing in part to a high sensitivity to perturbation by measurement probes. Magnetic resonance (MR) tech-niques, however, detect signal noninvasively from the fluid molecules and thereby overcome this obstacle to mea-surement. MR velocity maps and propagators (i.e., proba-bility density functions of displacement) were acquired of a flowing fluid in several regimes about the critical point, providing quantitative data on the transport and fluid dynamics in the system. Hexafluoroethane $\left(\mathrm{C}_{2} \mathrm{~F}_{6}\right)$ was pumped at $0.5 \mathrm{ml} / \mathrm{min}$ in a cylindrical tube through an MR system, and propagators as well as velocity maps were measured at temperatures and pressures below, near, and above the critical values. It was observed that flow of $\mathrm{C}_{2} \mathrm{~F}_{6}$ with thermodynamic properties far above or below the critical point had the Poiseuille flow distribution of an incompressible Newtonian fluid. Flows with thermody-namic properties near the critical point exhibit complex flow distributions impacted by buoyancy and viscous for-ces. The approach to steady state was also observed and found to take the longest near the critical point, but once it was reached, the dynamics were stable and reproducible. These data provide insight into the interplay between the critical phase transition thermodynamics and the $\ddot{\imath} \neg$, uid dynamics, which control transport processes.
\end{abstract}

\section{Introduction}

Supercritical fluids (SCF) are widely used for chromatog-raphy applications, extraction processes, and are finding increased use in oil recovery and in burgeoning seques-tration applications (Allen et al. 1988; Albert et al. 1994; Brunner 2005; Orr and Taber 1984; Parker et al. 2009; Ravagnani et al. 2009; Van der Meer 1995; Klusman 2003). The fluid dynamics of supercritical fluids has motivated significant work on the theoretical aspects (Zappoli 2003; Onuki 2002; Hohenberg and Halperin 1977; Barmatz et al. 2007; Beysens 2005; de Gennes 1975; Landau and Lifshitz 1959; Onuki 1998; Onuki and Ka-wasaki 1978; Zappoli et al. 1999), but experiments are limited, with a few exceptions (Kurganov and Kaptilnyi 1993; Okamoto et al. 2003; Kurganov and Kaptil'ny 1992). The thermodynamic phase of a pure fluid may be rep-resented by variables of density, pressure, and temperature $(\mathrm{q}, \mathrm{P}, \mathrm{T})$. On a pressure-density phase diagram, the pure liquid and pure vapor states are separated by a coexistence curve, which has a maximum called the critical point. This point is designated by its critical values $\left(\mathrm{q}_{\mathrm{c}}, \mathrm{P}_{\mathrm{c}}, \mathrm{T}_{\mathrm{c}}\right)$, and a fluid under equilibrium thermodynamic conditions with temperature and pressure above the critical values is called a supercritical fluid. Above the critical point, the fluid may exhibit transport characteristics similar to both gases and liquids; for instance, diffusivities and viscosities are similar to those of a gas, while densities are similar to those of a liquid. Supercritical fluids also possess favorable sol-vent characteristics, and as an alternative to current 
petroleum-based solvents, they may offer a lower environmental impact. One SCF solvent is supercritical $\mathrm{CO}_{2}$ (Maiwald et al. 2007), which is naturally occurring and is an inherent byproduct of some processes. Its abundance and relatively lower environmental toxicity makes it a viable option for use in applications such as food processing (Brunner 2005) and enhanced oil recovery (EOR) (Klusman 2003; Parker et al. 2009; Orr and Taber 1984). Supercritical $\mathrm{CO}_{2}$ is also used in fluid extraction processes and chromatography, which exploit the transport and solubility advantages of supercritical fluids (Allen et al. 1988; Albert et al. 1994). Storage of $\mathrm{CO}_{2}$ in a supercritical state in earth formations is currently being implemented as means to reduce $\mathrm{CO}_{2}$ in the atmosphere and thus mitigate global climate change (Van der Meer 1995; Ravagnani et al. 2009; Klusman 2003; Okwen et al. 2009). Enhanced understanding of the fluid dynamics and transport processes in SCFs can impact these applications.

Thermophysical properties such as specific heat, density, viscosity, and heat transfer coefficients are tunable by adjusting the pressure or temperature of the fluid in a range about the critical values (Jiang et al. 2008a). Experimentally, the effects of the thermophysical properties of a supercritical fluid on heat transfer under flowing conditions against and with gravity have been studied (Duffey and Pioro 2005; Pioro et al. 2004; Jiang et al. 2009; Liao and Zhao 2002). At a threshold, buoyancy in the fluid begins to impact the heat transfer and mass transport. Much work has been performed to numerically or theoretically (Dang and Hihara 2004; Jain and Rizwan 2008; Bae et al. 2005; He et al. 2008; Fard 2009; Bae and Kim 2009; Bruch et al. 2009) predict and validate the thermophysical behavior of near-critical fluids, including buoyancy effects (Barmatz et al. 2007; Beysens 2005; de Gennes 1975; Landau and Lifshitz 1959; Hohenberg and Halperin 1977). Recently, some focus has shifted from larger scale experiments to mini-tubes (Jiang et al. 2008b) and porous tubes (Jiang et al. 2004, 2006, 2008a). Work to date has validated numerical and theoretical models against experimental thermophysical data, but fluid dynamic data are very limited. In regard to velocity distributions of a flowing fluid near the critical point, several groups offer reliable theoretical or numerical models for turbulent or laminar entrance flows (He et al. 2008; Bae et al. 2005; Howell and Lee 1999; Jiang et al. 2008a; Tanaka et al. 1973; Lee and Howell 1996a, b; Zhou and Krishnan 1995), but the only experimental data available are those using invasive measurements, such as Pitot tubes (Kurganov and Kaptilnyi 1993; Kurganov and Kaptil'ny 1992). The experimental velocity maps presented in this paper were obtained using noninvasive magnetic resonance (MR) and provide spatial velocity-encoded data.
MR performed on supercritical fluids has shown that, in porous media, the critical temperature within pore spaces was depressed relative to that of the bulk fluid, and that the magnitude of the shift was dependent on the void size. (Dvoyashkin et al. 2007a, b). This work on SCFs in porous media was for non-flowing conditions, and little research has been performed utilizing MR to study SCF flows. MR imaging has been used to investigate porous media subject to SCF $\mathrm{CO}_{2}$ intrusion, although transport was detected indirectly via water signal intensity and relaxation components (Suekane et al. 2009; Hussain et al. 2011). Minimal data exist for flowing SCFs for applications other than heat transfer. MR has been used to spectrally detect dissolved compounds in applications using $\mathrm{CO}_{2}$ for supercritical fluid chromatography (SFC) (Allen et al. 1988; Albert et al. 1994; Maiwald et al. 2007; Yonker and Linehan 2005). However, application of MR to flowing supercritical fluids with the purpose of obtaining transport properties and fluid dynamics has only recently been demonstrated (Rassi et al. 2012).

\section{Fluid dynamic theory}

The conservation equations of mass (1), momentum (2), and energy (3) for steady state compressible flow of a supercritical fluid in a cylindrical tube are as follows:

$$
\begin{aligned}
& \frac{\partial(r \rho u)}{\partial x}+\frac{\partial(r \rho v)}{\partial r}=0 \\
& \rho u \frac{\partial u}{\partial x}+\rho v \frac{\partial u}{\partial r}=\frac{1}{r} \frac{\partial}{\partial r}\left(r \mu \frac{\partial u}{\partial r}\right)-\rho g-\frac{\mathrm{d} p}{\mathrm{~d} x} \\
& \rho u \frac{\partial h}{\partial x}+\rho v \frac{\partial h}{\partial r}=\frac{1}{r} \frac{\partial}{\partial r}\left(r \frac{\lambda}{C_{p}} \frac{\partial h}{\partial r}\right)+u \frac{\mathrm{d} p}{\mathrm{~d} x}+\mu\left(\frac{\partial u}{\partial r}\right)^{2}
\end{aligned}
$$

Here, $\rho$ is density, and $u$ and $v$ are the longitudinal and radial velocity components, respectively. The specific enthalpy is $h$, the thermal conductivity is $\lambda$, and the specific heat is $C_{p}$. Under supercritical conditions, buoyancy effects due to heating at the wall may significantly alter the flow profile. The system of equations suffices for laminar flow, but may also be time and Favre averaged to model turbulent flow (Bae et al. 2005) and account for temperature and buoyancy-dependent variables. The time-averaged fluctuation terms for mass flux $\overline{\rho^{\prime} u^{\prime}}$ and $\overline{\rho^{\prime} v^{\prime}}$ as well as the heat flux $\overline{\rho^{\prime} h^{\prime}}$ represent the impact of buoyancy on the turbulent equations, and while the classical transition threshold for laminar to turbulent flow in pipes is $R e \approx 2,300$, strong buoyancy effects may reduce the threshold as low as $R e \approx 200-400$ (Jiang et al. 2008c).

Mixed advection and convection for these supercritical flows deal with forced advection due to a pump, which 
imposes a pressure gradient, and natural convection due to buoyancy, which is enhanced by density fluctuations near the critical point. The Richardson number $R i=\frac{G r}{R e^{2}}$ is a dimensionless parameter that compares the natural convection (buoyancy forces) as calculated by the Grashof number $G r=\frac{\left(\rho_{b}-\bar{\rho}\right) \rho_{b} g D^{3}}{\mu_{b}^{2}}$ and the forced advection as represented by the Reynolds number $R e=\frac{\rho u D}{\mu}$ (Bae et al. 2005). An empirical correction has been determined for supercritical flow of carbon dioxide $R i=\frac{G r}{R e^{2.7}}$ (Jackson and Hall 1979). In the definitions of the dimensionless groups,

$\bar{\rho} \approx\left\{\begin{array}{cc}\frac{\left(\rho_{w}+\rho_{b}\right)}{2}, & T_{w}>T_{c} \text { or } T_{b}<T_{c} \\ \frac{\left[\rho_{b}\left(T_{b}-T_{c}\right)+\rho_{w}\left(T_{c}-T_{w}\right)\right]}{T_{b}-T_{w}}, & T_{w}<T_{c}<T_{b}\end{array}\right.$

where the subscript $w$ refers to properties at the tube wall and $b$ to those in the bulk fluid.

At high mass flow rates, forced advection impacts the dynamics of the flowing system more than the free convection. Conversely, free convection dominates at low mass flow rates. A threshold therefore separates the two regimes that has been empirically determined for carbon dioxide (Jackson and Hall 1979), with $R i=\frac{G r}{R e^{2.7}}>10^{-5}$ indicating buoyancy influenced dynamics. For other fluids, the threshold will be different, but this has not been investigated.

Bae et al. (2005) solved the conservation equations using computational fluid dynamics code. Eight cases were studied, and parameters observed included density, viscosity, temperature, friction coefficient, and velocity profiles as a function of the radial coordinate. Of most importance to the work presented here are the data for $\boldsymbol{v}(\boldsymbol{r})$ and $\rho(\boldsymbol{r})$, the fluid velocity and density as a function of radius in the fully developed region far from the tube entrance. This case was for mixed upward convection of $\mathrm{CO}_{2}$ with heating at the wall of a 2-mm-diameter tube and the following conditions: $8 \mathrm{MPa}, 301.15 \mathrm{~K}$, and $R e=5,400$. The time-averaged density as a function of radial position shows that heating at the walls clearly decreases the density there, and the resulting density gradient produces buoyancy effects. For laminar flow, lower Reynolds number causes the drop in density near the critical point to shift toward the center of the tube (Lee and Howell 1996b). Bae et al. (2005) also numerically determine the statistics of density fluctuations for upward flow in a tube. It is the region spanning the critical point that is characterized by the greatest fluctuations in density, because small changes in pressure can produce large changes in density, i.e. the slope of the critical isotherm on a pressure-density phase diagram vanishes $(\mathrm{d} P / \mathrm{d} \rho=0)$ (Stanley 1971). The root-mean-squared density fluctuations (relative to the mean) at the center of the pipe were small; however, at the wall, where the temperature and pressure in their simulations were nearest the critical point, the density fluctuates up to $\sim 55 \%$.

Likewise, bulk density variation leads to buoyancy that strongly affects the velocity profile (Bae et al. 2005). In the fully developed region of the tube, for a fluid near its critical point, the profile develops into an " $\mathrm{M}$ " shape that maintains mass conservation and the balance of thermophysical and hydrodynamic properties. This has been studied experimentally by Kurganov and Kaptil'ny (1992) and numerically by Jiang et al. (2008c) as well as He et al. (2008). Downward flow and upward flow have been compared relative to buoyancy near the critical point, and Jiang et al. (2009) have done a numerical comparison illustrating the differences. With wall cooling, the fluid is denser near the walls than near the center of the pipe, and buoyancy thus causes upward acceleration near the center of the pipe and downward acceleration near the walls (vice versa for wall heating). The shape of the profile then depends on the direction of flow: for upward flow, wall heating will promote higher velocity at the walls and produce the "M-shaped" profile, and wall cooling will promote lower velocity near the walls and enhanced flow near the tube center. For downward flow, the effect of the two heat transfer conditions will be opposite.

\section{Methods}

MR techniques (Newling 2008; Stejskal and Tanner 1965; Callaghan 1991; Fukushima and Roeder 1981; Codd et al. 1999; Kuethe et al. 2005) were used to obtain spatially resolved velocity images, as well as bulk, ensemble-averaged propagators and self-diffusion coefficients in a supercritical fluid. All data were acquired on a Bruker Avance III $300 \mathrm{MHz}$ MR imaging spectrometer with a $5 \mathrm{~mm}{ }^{19} \mathrm{~F}$ radiofrequency (RF) coil and $1.5 \mathrm{~T} / \mathrm{m} x y z$ magnetic field gradients. Hexafluoroethane $\left(\mathrm{C}_{2} \mathrm{~F}_{6}\right)$ was chosen for these studies due to its favorable combination of critical properties, including a critical temperature near room temperature $T_{c}=19.9^{\circ} \mathrm{C}$ and a relatively low critical pressure $P_{c}=30.5$ bar (Fig. 1). It exhibits favorable MR relaxation times in the pressure range $10-75$ bar $\left(T_{1}=80-1,240 \mathrm{~ms}\right.$, $T_{2}=80-1,020 \mathrm{~ms}$ ), where both $T_{1}$ and $T_{2}$ increase at higher pressures and temperatures, and the high natural abundance and relatively strong NMR signal of the ${ }^{19} \mathrm{~F}$ nucleus, make it ideal for study by MR (Saikawa et al. 1979; Kuethe et al. 2005; Lemmon et al. 2013; Madani et al. 2008).

A tube flow system for the $\mathrm{C}_{2} \mathrm{~F}_{6}$ was designed for the MR spectrometer (Fig. 2). From the supply tank, pressure regulation and flow of the fluid through the system were achieved using an Isco 500D syringe pump. PEEK tubing 
of $1.524 \mathrm{~mm}$ ID was used within the NMR magnet, and stainless steel tubing was used outside of it, with back pressure maintained by a Thar ABPR-20-1 back pressure

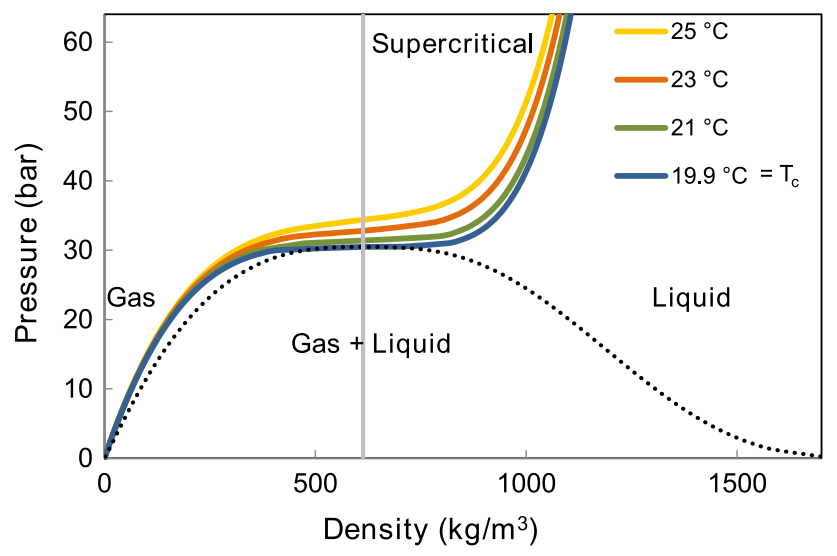

Fig. 1 Pressure-density phase diagram for $\mathrm{C}_{2} \mathrm{~F}_{6}$ showing the critical isotherm $\left(T_{c}=19.9^{\circ} \mathrm{C}\right)$ as well as select isotherms corresponding to temperature values used in the study. The vertical, gray line indicates the critical density, and the dotted line shows the liquid-vapor coexistence curve. The critical point is located at the intersection of the two (Lemmon et al. 2013).

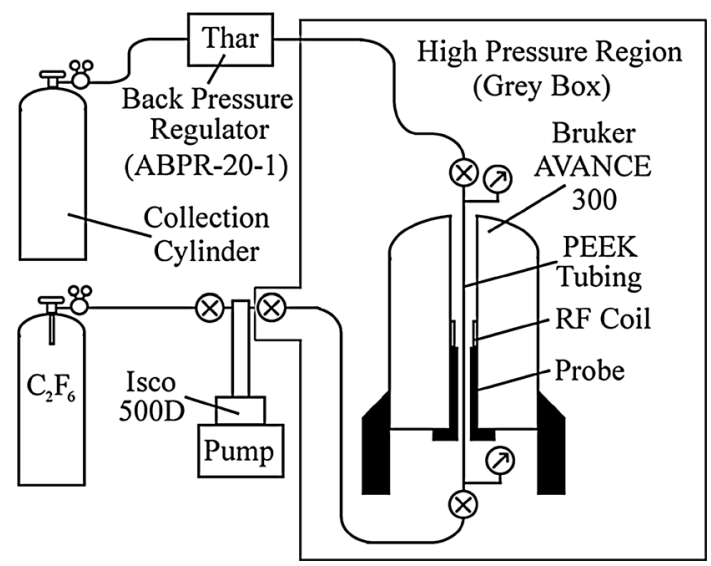

Fig. 2 Supercritical flow loop schematic regulator. Upon exiting the back pressure regulator, the depressurized $\mathrm{C}_{2} \mathrm{~F}_{6}$ was collected in a gas cylinder and reused. Under flow conditions, the fluid was pumped vertically upward through the magnet with an inlet flow rate of $0.5 \mathrm{ml} / \mathrm{min}$, and MR measurements were made with various combinations of fluid pressure and temperature $\left(P, T_{b}\right)$ and external tube wall temperature $\left(T_{w}\right)$ as monitored by pressure transducers and thermocouples at select points in the flow loop. Near the critical point, the $\mathrm{C}_{2} \mathrm{~F}_{6}$ may exhibit compressibility effects, so the local flow rate within the MR apparatus will generally be a function of $P / T$, but these variations in the flow are measured directly using the velocity images.

All MR measurements were based on a pulsed gradient spin-echo (PGSE) sequence (Fig. 3). The essence of the sequence is a pair of pulsed magnetic field gradients of amplitude $g$, duration $\delta$, and time separation $\Delta$ that encodes for molecular displacements in the phase and amplitude of the NMR signal. This encoding may be expressed in terms of a reciprocal displacement vector $\overleftarrow{q}=\gamma \delta \overleftarrow{g}$, where $\gamma$ is the characteristic nuclear gyromagnetic ratio, and $q$ is typically varied by changing $g$ at constant $\delta$. The resulting signal, $E(q)$, contains information about coherent motions (advection) as well as stochastic motions (diffusion, turbulence, etc.) averaged over the ensemble of fluid molecules within the detection volume (Callaghan 2011).

The axial advective velocity field in a cross section of the tube was imaged with a standard approach that uses a PGSE preparation step followed by a spin-echo imaging sequence. Two images are acquired with opposite pulsed gradient polarity $\left(q_{1}=-q, q_{2}=+q\right)$, and the difference in complex phase $\left(\phi_{2}-\phi_{1}\right)$ is used to calculate velocity within each pixel of the image matrix.

$v=\frac{\left(\phi_{2}-\phi_{1}\right)}{\Delta\left(q_{2}-q_{1}\right)}$

An RF excitation pulse duration of $1 \mathrm{~ms}$ was used, and velocity was encoded using a displacement observation
Fig. 3 The PGSE sequence is standard for MR motion sensitive measurements. A $90^{\circ}-$ $180^{\circ}$ pair of RF pulses produce a signal echo at time $2 \tau$ while the pair of pulsed gradients of duration $\delta$ and separation $\Delta$ encode for displacements
RF

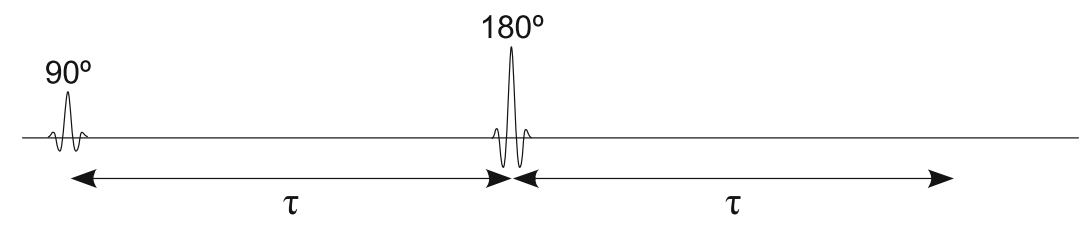

g

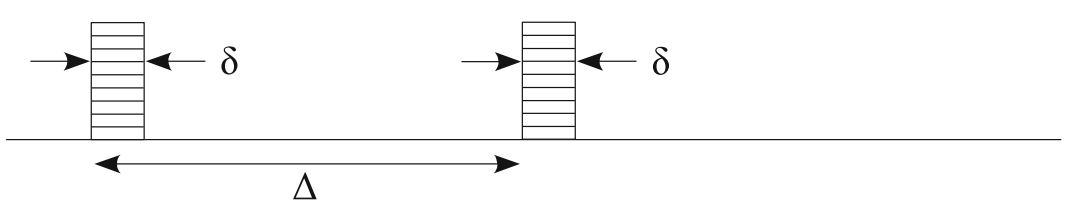

signal

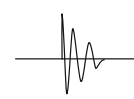


time $\Delta=7.41 \mathrm{~ms}$, pulsed gradient duration $\delta=0.5 \mathrm{~ms}$, and maximum gradient $g=0.211 \mathrm{~T} / \mathrm{m}$, giving a velocity resolution of $\Delta v=0.250 \mathrm{~mm} / \mathrm{s}$. The image slices were $500 \mu \mathrm{m}$ thick with an isotropic in-plane spatial resolution of $62.5 \mu \mathrm{m}$. Correction of residual phase error due to imaging gradients was done by subtracting a "no-flow" velocity image, where the acquisition was made using the same imaging parameters on stationary fluid.

Propagators were acquired on bulk fluid within the tube and represent an ensemble-averaged histogram of particle displacements along the pulsed gradient direction over the given observation time $\Delta$. Taking the gradient direction to be $Z$, along the axis of the tube, the propagator $P(Z, \Delta)$ is obtained using the Fourier relation with the PGSE signal, $E(q, \Delta)$ (Callaghan 2011).

$E(q, \Delta)=\int P(Z, \Delta) \exp (i q Z) \mathrm{d} Z$

The resulting $P(Z, \Delta)$ is a statistical distribution of particle displacements, but axes may be scaled by the observation time $\Delta$ to instead report mean particle velocities.

One advantage of propagators over velocity mapping is related to the measurement timescale, $\Delta$, since without the constraint of spatially resolving the signal, it is possible to probe dynamics at longer observation times to explore the interplay of diffusion and advection, i.e., hydrodynamic Taylor dispersion. The typical propagator characteristics for Poiseuille flow in a capillary as a function of $\Delta$ have previously been elucidated (Codd et al. 1999). When $\Delta$ is short relative to the flow timescale, the propagator shape is defined primarily by molecular Brownian motion and appears as a shifted Gaussian. At longer timescales, the statistics of the advective profile emerge, which for Poiseuille flow is a hat function convolved with the diffusive Gaussian. When $\Delta$ is long relative to the timescale for diffusion across the pipe, effects of Taylor dispersion may be observed, where random sampling of streamlines leads to a reduction in the width of the propagator relative to that of pure diffusion-so-called "motional narrowing". As well, a peak at lower velocities emerges due to collisions with the walls. Propagators in the present study were acquired from fluid within a $15-\mathrm{mm}$-thick slice along the tube length using a gradient pulse duration $\delta=1 \mathrm{~ms}$, an observation time in the range of $\Delta=10-100 \mathrm{~ms}$, and $128 q$-points collected with a maximum gradient magnitude of $g=0.945 \mathrm{~T} / \mathrm{m}$, giving a velocity resolution of $\Delta \mathrm{v}=3-30 \mu \mathrm{m} / \mathrm{s}$.

Bulk measurements of the self-diffusion coefficient of the stationary fluid were also made, which represent a statistical measure of molecular Brownian motion. Here, the PGSE signal is recorded as a function of $q$, and leastsquares regression is used to determine $D$ from the Stejskel-Tanner relation.
$\frac{E(q)}{E(0)}=\exp \left(-q^{2} D(\Delta-\delta / 3)\right)$

Because of high sensitivity to temperature or pressure variations near the critical point, diffusion measurements were made using a variant of the PGSE sequence called "double-PGSE", which suppresses the effects of coherent, convective flows and detects molecular self-diffusion only (Callaghan 2011). A displacement observation time of $\Delta=100 \mathrm{~ms}$ was used, with a gradient pulse duration of $\delta=0.5 \mathrm{~ms}$.

The relevant thermodynamic variables in the system are the pressure $(P)$ and temperature of the $\mathrm{C}_{2} \mathrm{~F}_{6}$ fluid at the entrance to the magnet $\left(T_{b}\right)$, as well as the temperature at the exterior wall of the tubing within the magnet $\left(T_{w}\right)$. The fluid temperature $\left(T_{b}\right)$ was in equilibrium with the ambient room temperature, which was controlled to $\pm 0.5^{\circ} \mathrm{C}$. The temperature of the exterior walls of the tubing $\left(T_{w}\right)$ inside the spectrometer was controlled to $\pm 0.1{ }^{\circ} \mathrm{C}$ by the water-cooling system that regulates temperature of the magnetic field gradient coils, as monitored directly by a thermocouple positioned near to the RF coil during system testing. Differences in the fluid/wall temperature were used to control heat transfer, either to the fluid from the environment $\left(T_{b}<T_{w}\right)$ or vice versa $\left(T_{b}>T_{w}\right)$. Due to thermal resistance of the tube walls (PEEK, $0.825 \mathrm{~mm}$ thick), the equilibrium temperature of the internal boundary will be slightly closer to $T_{b}$ than the stated $T_{w}$. MR experiments on the $\mathrm{C}_{2} \mathrm{~F}_{6}$ were conducted by independently varying the values of $P, T_{b}$, and $T_{w}$ to observe their effects on the fluid flow.

With regard to nomenclature, a fluid is said to be in the supercritical state when its temperature and pressure are greater than the critical values (i.e., $T>T_{c}$ and $P>P_{c}$ ). In terms of the parameters varied in this work, we refer to three regimes: "sub-critical", "near-critical", and "supercritical". For example, if the $\mathrm{C}_{2} \mathrm{~F}_{6}$ has $P=25$ bar and $T=23{ }^{\circ} \mathrm{C}$, the fluid is technically not in the supercritical state (because $P<P_{c}$ ), but we may specify that the pressure was subcritical and the temperature was supercritical. The term "near-critical" refers to a range close to the critical values, and in the present use, this means $T=(19.9 \pm 1){ }^{\circ} \mathrm{C}$ or $P=(30.5 \pm 2)$ bar.

\section{Results}

Prior to studying the system under flow conditions, diffusion measurements were made on stagnant fluid to experimentally confirm the critical phase transition via NMR. Using the flow compensated double-PGSE measurement, the $\mathrm{C}_{2} \mathrm{~F}_{6}$ diffusion coefficient was determined as a function of pressure in a range about $P_{c}$ and at temperatures $T=15$ and $25^{\circ} \mathrm{C}$ (Fig. 4). 


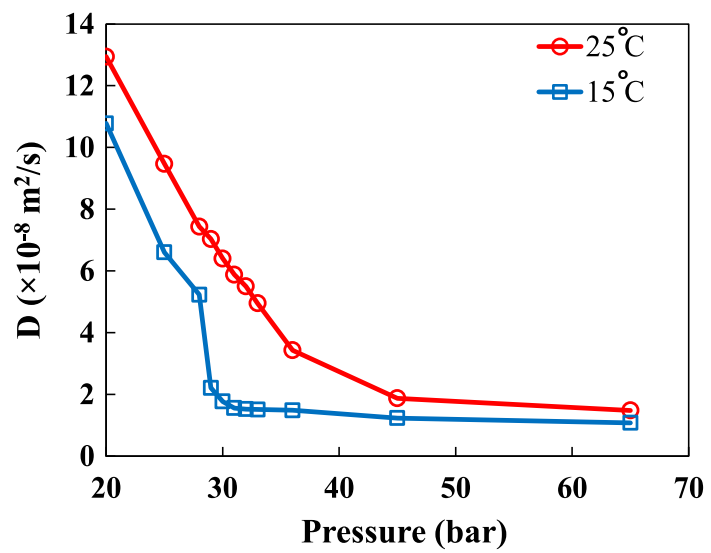

Fig. 4 Diffusion coefficient as a function of pressure for $\mathrm{C}_{2} \mathrm{~F}_{6}$ at temperatures above $\left(25^{\circ} \mathrm{C}\right)$ and below $\left(15^{\circ} \mathrm{C}\right)$ the critical temperature

Velocity maps were acquired for a constant fluid temperature above the critical point $\left(T_{b}=23{ }^{\circ} \mathrm{C}>T_{c}\right)$, with various combinations of pressure and external temperature values chosen below, near, and above the critical values $\left(P=25,29\right.$, and 45 bar; $T_{w}=15,21$, and $\left.25^{\circ} \mathrm{C}\right)$. The velocity maps were analyzed, and a diametral profile of the cross-sectional velocity field across the tube was recorded for each image (Fig. 5). For laminar flow of a Newtonian, incompressible fluid, the predicted velocity profile is Poiseuille and is given by $v(r)=v_{\max }\left(1-\left(\frac{r}{R}\right)^{2}\right)$ where $r$ is the coordinate in the radial direction, $R$ is the radius of the tubing, and the maximum velocity occurs at the center of the tubing. Poiseuille profiles calculated based on the volumetric flow rate of the pump are overlaid on the measured profiles for comparison.

To demonstrate the effect of more finely resolved parameter variation near the critical point, velocity maps were also measured by setting all three thermodynamic parameters $P, T_{b}$, and $T_{w}$ to their near-critical values $\left(P=29\right.$ bar; $\left.T_{b}=T_{w}=20{ }^{\circ} \mathrm{C}\right)$, then varying the parameters one at a time in a range about the critical point. The diametral velocity profiles for the various conditions are shown in Fig. 6.

Propagators were acquired for all flow conditions corresponding to the velocity maps in Fig. 5. At a constant fluid temperature of $T_{b}=23{ }^{\circ} \mathrm{C}$, and external temperatures of $T_{w}=15,21$, and $25^{\circ} \mathrm{C}$, the propagators are shown for pressures $P=25$ bar, 29 bar, and 45 bar (Fig. 7). In each experimental condition, the displacement observation time was varied within the range $\Delta=10-100 \mathrm{~ms}$ to probe a range of displacement timescales. The full set of propagators plotted in Fig. 7 show the effects of variable pressure $P$, external temperature $T_{w}$, and observation time $\Delta$. To highlight just the effect of variable pressure, the propagators corresponding to temperatures $T_{b}=23{ }^{\circ} \mathrm{C}$ and
$T_{w}=21{ }^{\circ} \mathrm{C}$ (i.e., those closest to the critical temperature and corresponding to minimal heat transfer) are compared in Fig. 8 for the observation time limits, $\Delta=10$ and $100 \mathrm{~ms}$.

The time for the flow to reach equilibrium depends on the thermodynamic conditions, taking the longest when $P$, $T_{b}$, and $T_{w}$ were nearest the critical point. Velocity maps (Fig. 9) and propagators (Fig. 10) were therefore acquired at $P=29$ bar to observe the process of equilibration and determine when the flow had settled into a steady state. The measurement was repeated under identical conditions to check whether the steady-state equilibrium was reproducible or if the flow was unstable and would be different from run to run. The flow was considered to have reached steady state if a) two sequential propagators showed equivalent flow characteristics and b) the final-state propagators for separate runs were equivalent. It was found that the system required $270 \mathrm{~min}$ to reach steady state.

\section{Discussion}

The continuous decrease in diffusivity near the critical point under no-flow conditions has been observed previously in an NMR study with $n$-pentane (Dvoyashkin et al. 2007a), but was performed here for $\mathrm{C}_{2} \mathrm{~F}_{6}$ to experimentally confirm that the corresponding temperatures produce the supercritical/subcritical phases (Fig. 4). At a constant temperature of $15^{\circ} \mathrm{C}$, the pressure range of $20-65$ bar traverses the constant-pressure region on a subcritical isotherm, which is associated with a gas-to-liquid phase change. Under these conditions, a discontinuous drop in the diffusivity with increasing pressure was observed, which corresponds to the transition across the two-phase region. At the higher temperature of $25^{\circ} \mathrm{C}$, the fluid transitioned from gas to liquid within the supercritical region with a continuous decrease and no sudden drop in diffusivity. These differences in the diffusivity curves as a function of pressure confirmed that the temperatures 15 and $25^{\circ} \mathrm{C}$ used for the flowing conditions were in the subcritical and supercritical regimes, respectively (Lemmon et al. 2013).

The velocity maps presented in this study represent noninvasive, spatially resolved characterization of flow in near-critical and supercritical fluids and give supporting evidence to previously reported numerical results (Bae et al. 2005; He et al. 2008; Jiang et al. 2008c). The expected flow profile for an incompressible fluid without buoyancy effects is Poiseuille; however, Fig. 5 shows how heat transfer may alter that profile, as well as how the relative sensitivity to heat transfer depends on proximity to the critical point (i.e., $P_{c}=30.5 \mathrm{bar}$ and $T_{c}=19.9^{\circ} \mathrm{C}$ for $\mathrm{C}_{2} \mathrm{~F}_{6}$ ). The profiles in Fig. 5a-c depict three heat transfer scenarios for the fluid at $T_{b}=23{ }^{\circ} \mathrm{C}$. At $T_{w}=15{ }^{\circ} \mathrm{C}$, there 


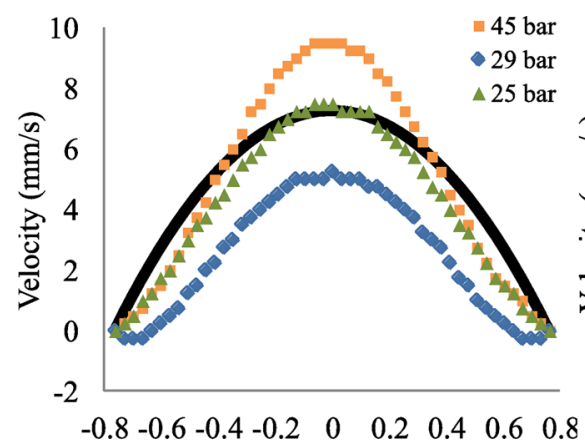

Distance from Centerline $(\mathrm{mm})$

(a) wall-cooling, $T_{w}=15^{\circ} \mathrm{C}$

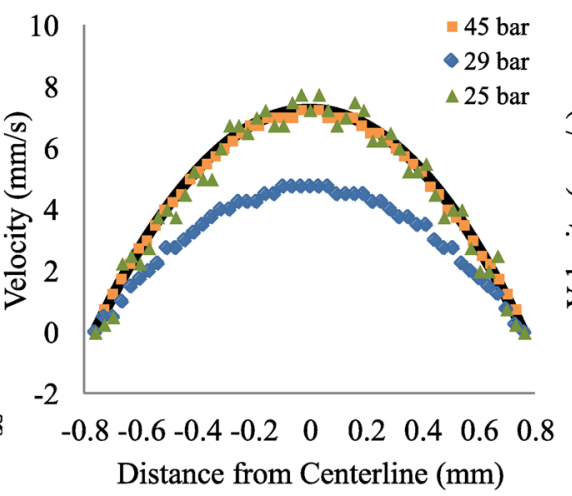

(b) minimal heat transfer, $\mathrm{T}_{\mathrm{w}}=21^{\circ} \mathrm{C}$

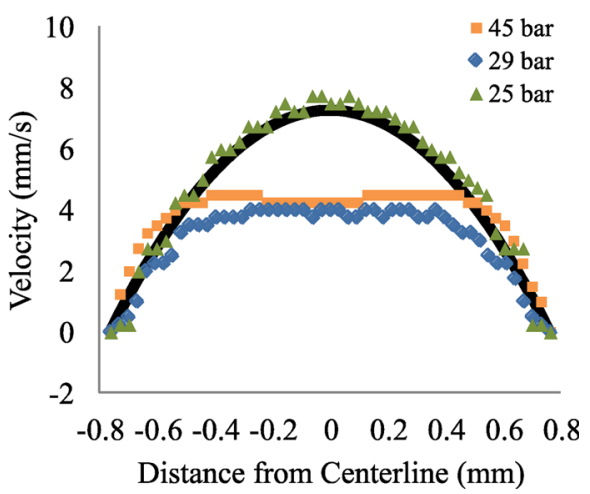

(c) wall-heating, $\mathrm{T}_{\mathrm{w}}=25^{\circ} \mathrm{C}$

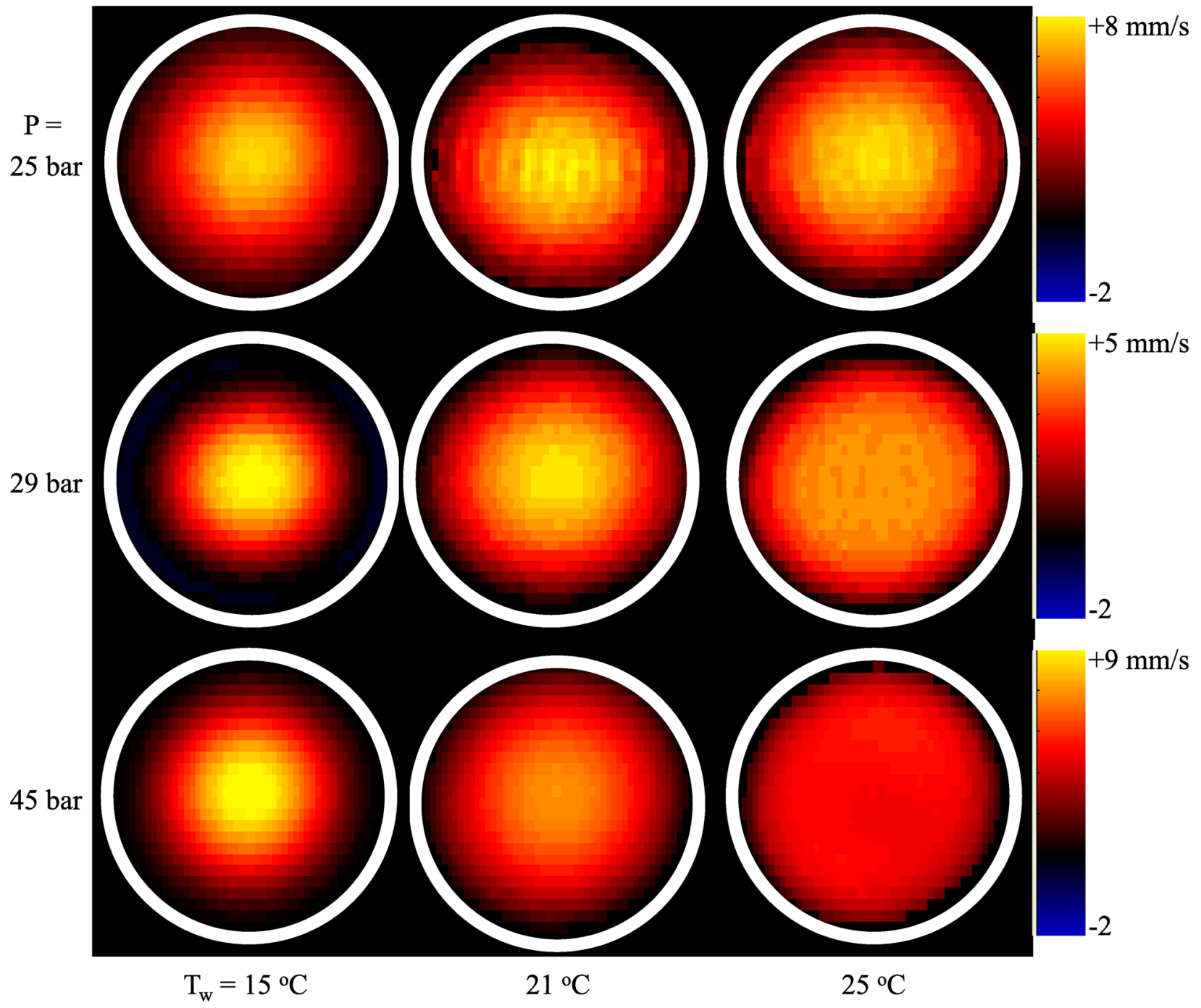

(d) Velocity maps

Fig. 5 Velocity profiles for upward flow of $\mathrm{C}_{2} \mathrm{~F}_{6}$ at a fluid temperature $T_{b}=23{ }^{\circ} \mathrm{C}$, varied pressures $P=25,29$, and $45 \mathrm{bar}$ (below, near, and above $P_{c}$ ), and a coil temperature of $\mathbf{a} 15{ }^{\circ} \mathrm{C}$, b $21^{\circ} \mathrm{C}$, and c $25^{\circ} \mathrm{C}$. The profiles were taken across the diameter of the $2 \mathrm{D}$ velocity profiles shown in $\mathbf{d}$. In $\mathbf{a}-\mathbf{c}$, the Poiseuille flow profile predicted for incompressible flow at $0.5 \mathrm{ml} / \mathrm{min}$ is included for comparison (solid black line) 

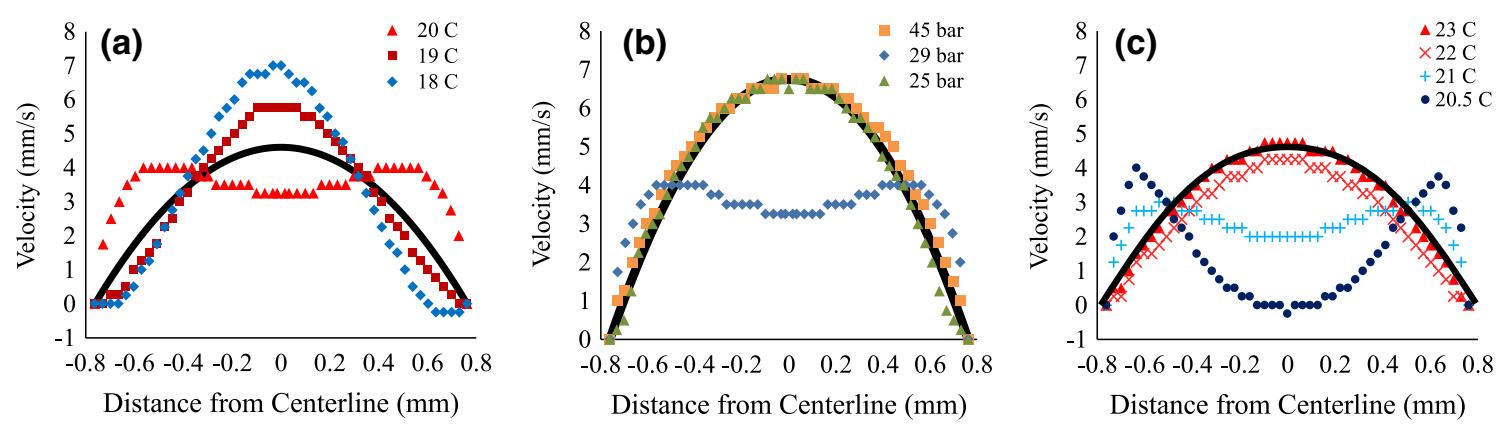

Fig. 6 Velocity profiles for upward flow of $\mathrm{C}_{2} \mathrm{~F}_{6}$ near the critical point: a $P=29$ bar, $T_{b}=20{ }^{\circ} \mathrm{C}$ with varied coil temperature; b $T_{b}=T_{w}=20^{\circ} \mathrm{C}$ with varied pressure; and c $P=29$ bar, $T_{w}=21^{\circ} \mathrm{C}$ with varied fluid temperature. Poiseuille flow profiles

are included for comparison (solid black lines): in $\mathbf{b}$ the profile is for incompressible flow at $0.5 \mathrm{ml} / \mathrm{min}$, while in $\mathbf{a}$ and $\mathbf{c}$ the profile is for compressible flow in the absence of wall-heating or wall-cooling effects
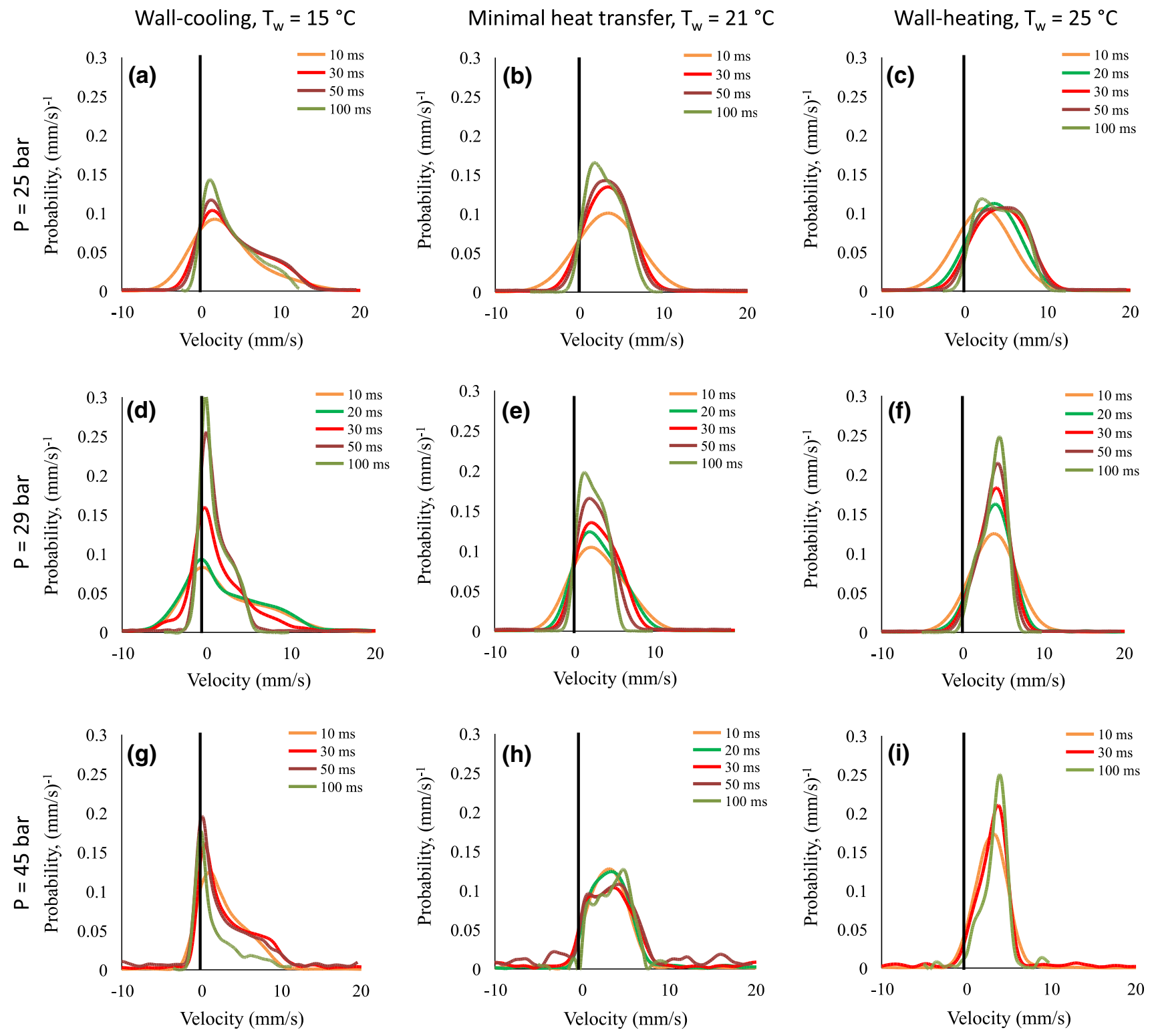

Fig. 7 Propagators for upward flow of $\mathrm{C}_{2} \mathrm{~F}_{6}$ at a fluid temperature $T_{b}=23{ }^{\circ} \mathrm{C}$ and pressure $P=25$ bar $(\mathbf{a}-\mathbf{c}), 29$ bar $(\mathbf{d}-\mathbf{f})$, and 45 bar (g-i). Columns correspond to conditions of wall-cooling (left,
$T_{w}=15^{\circ} \mathrm{C}$ ), minimal heat transfer (center, $T_{w}=21^{\circ} \mathrm{C}$ ), and wall heating (right, $T_{w}=25^{\circ} \mathrm{C}$ ) 
Fig. 8 Propagators for upward flow of $\mathrm{C}_{2} \mathrm{~F}_{6}$ at pressures 25, 29, and 45 bar with a fluid temperature of $T_{b}=23{ }^{\circ} \mathrm{C}$, a coil temperature of $T_{w}=21{ }^{\circ} \mathrm{C}$, and at an observation time $\Delta$ of a $10 \mathrm{~ms}$ and b $100 \mathrm{~ms}$

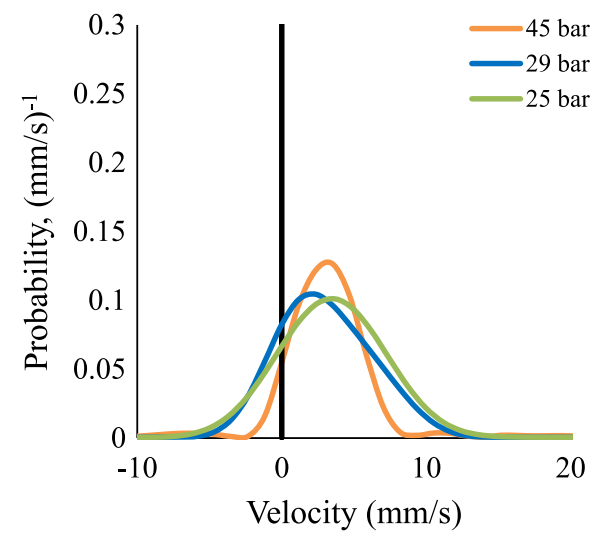

(a) $\Delta=10 \mathrm{~ms}$

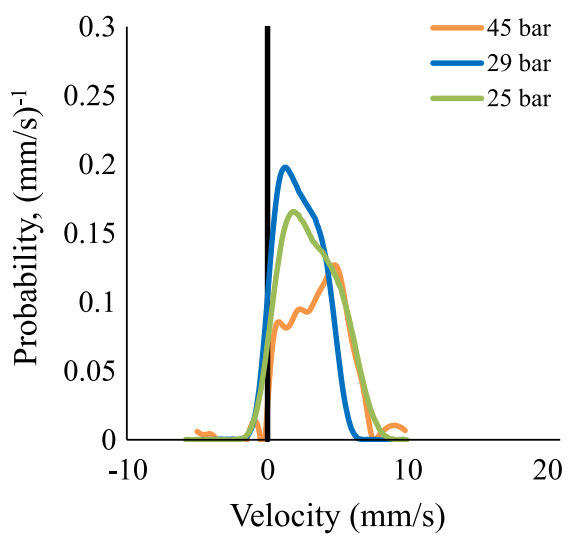

(b) $\Delta=100 \mathrm{~ms}$
Fig. 9 Velocity maps for upward flow of $\mathrm{C}_{2} \mathrm{~F}_{6}$ showing the approach to steady state near the critical point at $P=29 \mathrm{bar}$, $T_{b}=20^{\circ} \mathrm{C}$, and $T_{w}=20{ }^{\circ} \mathrm{C}$. The map labeled " $280 \mathrm{~min}$. (second run)" corresponds to a repeated trial observing the equilibration of the system

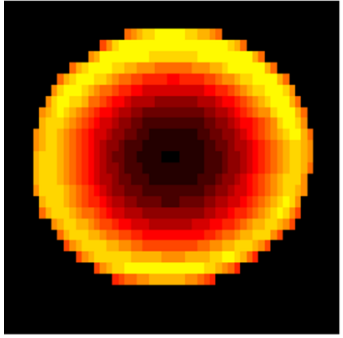

$0 \mathrm{~min}$.

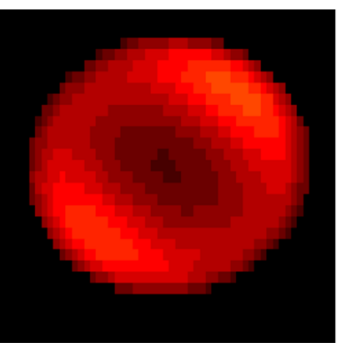

$210 \mathrm{~min}$

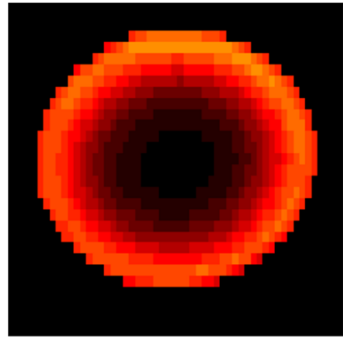

$70 \mathrm{~min}$.

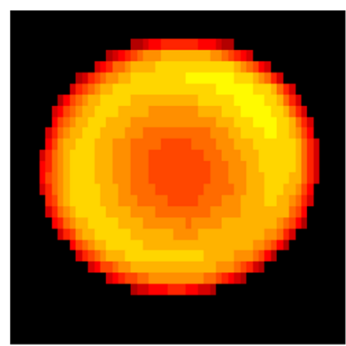

$280 \mathrm{~min}$.
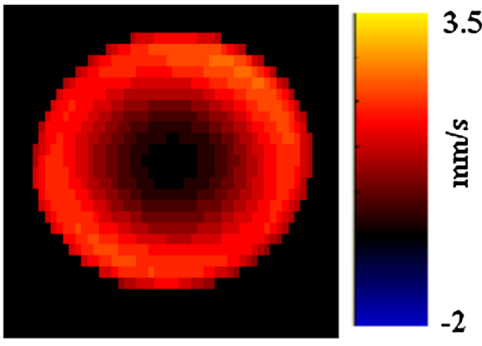

$140 \mathrm{~min}$.
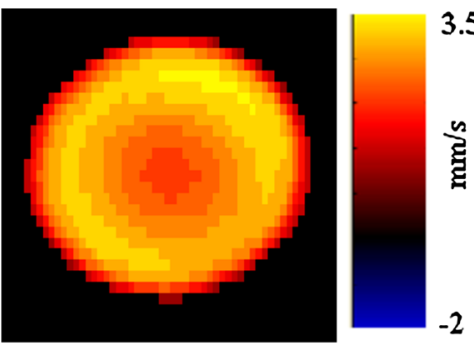

280 min. ( $2^{\text {nd }}$ run)

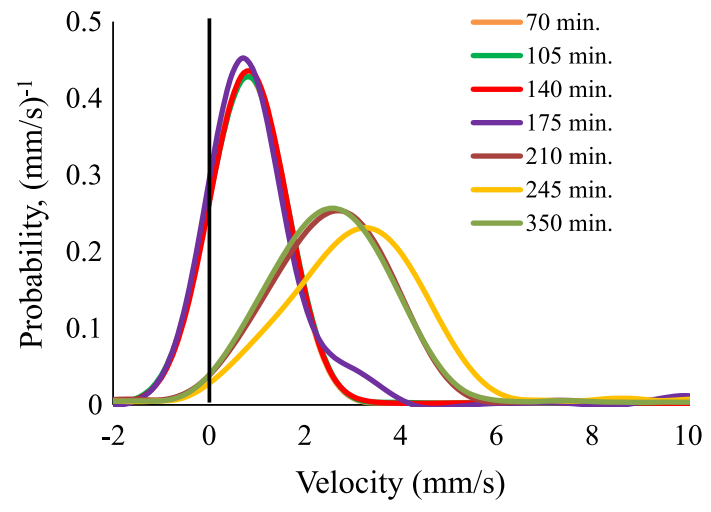

Fig. 10 Propagators for upward flow of $\mathrm{C}_{2} \mathrm{~F}_{6}$ showing the approach to steady state near the critical point at $P=29$ bar, $T_{b}=20^{\circ} \mathrm{C}$, and $T_{w}=20^{\circ} \mathrm{C}$. The displacement observation time was $\Delta=50 \mathrm{~ms}$ were cooling effects at the wall boundary for all three pressures (Fig. 5a). The cooler fluid near the walls is denser, and the effect of buoyancy leads to decreased fluid velocity in this region, which is associated with a nonPoiseuille (non-parabolic) profile. For $T_{w}=21{ }^{\circ} \mathrm{C}$, there was minimal heat transfer to/from the fluid (Fig. 5b). Correspondingly, there is minimal buoyancy effect, and all three profiles are Poiseuille (parabolic). The profile for the near-critical pressure $(P=29$ bar $)$ shows a much lower mean velocity. This is because of fluid compressibility near the critical point for which the mass flux $G=\rho v$ is conserved and indicates an increase in density and consequent decrease in velocity, but the profile remains qualitatively parabolic. At $T_{w}=25^{\circ} \mathrm{C}$, there was heat transfer to the fluid at the wall (Fig. 5c). A temperature increase near the 
walls relative to the tube center produces a buoyancy effect opposite of the cooling case, with increased flow velocity near the wall.

In each temperature scenario in Fig. 5, the fluid pressure relative to the critical pressure affects sensitivity to heat transfer. The fluid at 25 bar corresponds to a high-pressure gas, and it appears to behave as an incompressible fluid and to be relatively insensitive to the different heat transfer conditions. This is evidenced by close agreement with the Poiseuille profile under each condition. The fluid at 29 bar is nearest the critical pressure, and the mean velocity is notably lower than the reference Poiseuille profile in each case. Since a fluid near its critical point is known to have enhanced compressibility, a reduction in the mean velocity is expected. The fluid at this near-critical pressure is also the most sensitive to heat transfer. Under wall-cooling conditions (Fig. 5a), the fluid at the walls reverses direction with respect to the upward advection, while with wall heating (Fig. 5c), there is enhanced upward velocity near the wall. The fluid at 45 bar is well above the critical pressure. It is more sensitive to heat transfer than the 25 bar fluid but less sensitive than the 29 bar fluid and behaves like an incompressible fluid under neutral heat transfer conditions as shown by agreement with the predicted Poiseuille profile in Fig. $5 b$.

A notable feature of the flow at 45 bar with wall heating (Fig. 5c) is the "blunting" of the profile near the center and increase in velocity near the walls. This is associated with buoyancy effects near the heated wall generating faster flow and the onset of an "M-shaped" velocity profile due to the interaction of pressure driven and buoyancy-driven flow as discussed in detail below (Fig. 6). The near-critical 29 bar flow with wall heating (Fig. 5c) in contrast shows significant blunting of the velocity profile but not the higher velocity near the heated tube walls. Although the inlet $R e_{0}$ for all system pressures indicates that the flows are laminar, the profile at 29 bar with wall heating (Fig. 5c) suggests that the temperature gradient from the pipe center to the wall is smaller at 29 bar than 45 bar, based on stronger buoyancy forces generating the faster velocity near the wall at 45 bar. This effect is likely due to enhanced mixing in the near-critical 29 bar flow due to the large fluctuations in density and consequent velocity fluctuations at the critical phase transition.

Figure 6 shows parameter variation in a narrower range about the critical point. The reduction of viscosity that is characteristic of near-critical fluids (Landau and Lifshitz 1959 ) is manifest by reduction of shear stress near the walls. Figure 6a shows the effect of decreasing the wall temperature from $T_{w}=20-18{ }^{\circ} \mathrm{C}$ while the bulk fluid is near its critical temperature and pressure $\left(T_{b}=20^{\circ} \mathrm{C}, P=29 \mathrm{bar}\right)$. When $T_{w}=T_{b}=20^{\circ} \mathrm{C}$, a "zero heat transfer" condition is expected; however, temperature gradients may exist that are below the measurement resolution of $\pm 0.5{ }^{\circ} \mathrm{C}$ for the experiment. The result (Fig. $6 \mathrm{a}, T_{w}=20^{\circ} \mathrm{C}$ ) is a measured velocity profile that indicates (effectively) wall-heating conditions, where viscosity and density are reduced near the walls relative to the tube center. Correspondingly, the fluid velocity is more rapid near the walls and slower near the tube center, resulting in a characteristic "M" shape profile. The opposite is observed for a cooling wall boundary, where the denser fluid is near the walls and the less dense fluid is in the center of the tube (Fig. $6 \mathrm{a}, T_{w}=18^{\circ} \mathrm{C}$ ). Under these conditions, the velocity profiles show that the fluid near the walls slows down and in some cases reverses direction while the less dense fluid in the center of the tube speeds up. Figure $6 \mathrm{~b}$ shows the effect of changing pressure for equal wall and fluid temperatures, $T_{w}=T_{b}=20^{\circ} \mathrm{C}$. Again, small temperature gradients have little effect at pressures far from $P_{c}(P=25$ and 45 bar), but close to it ( $P=29$ bar), the effects are large due to the density fluctuations near the critical point, as evidenced by the "M"-shaped, non-Poiseuille profile. Lastly, Fig. 6c shows that varying $T_{b}$ (with fixed $T_{w}=21{ }^{\circ} \mathrm{C}$ ) also produces a transition from wall heating to wall cooling. The M-shaped wall-heating profile is most pronounced when the fluid conditions $\left(T_{b}, P\right)$ are closest to the critical point.

Under all experimental conditions given thus far, the low pump flow rate of $0.5 \mathrm{ml} / \mathrm{min}$ is expected to produce a laminar entrance flow so long as the Reynolds number remains low $(R e<2,300)$. Near the critical point, both the density and the viscosity fluctuate, and there is uncertainty in the Reynolds number in that regime; however, a stable reference Reynolds number, $R e_{0}$, was defined using the inlet parameters (Table 1), and these values were found to be far below the classical turbulent transition threshold. The diameter of the tube was $D=1.524 \mathrm{~mm}$, the mean velocity was $v=4.625 \mathrm{~mm} / \mathrm{s}$, and the density $\rho$ and dynamic viscosity $\mu$ values for $\mathrm{C}_{2} \mathrm{~F}_{6}$ were obtained from the National Institute for Standards and Technology (Lemmon et al. 2013). The maximum velocity was calculated using the $0.5 \mathrm{ml} / \mathrm{min}$ flow rate and assuming incompressible flow, and it therefore represents the maximum possible value (in practice, a compressible fluid will have a lower flow rate). The associated Grashof $(G r)$ and Richardson (Ri) numbers were also calculated (Table 1), and it is clear by the large Richardson number near the critical pressure (i.e., $P \approx 29$ bar) that the buoyancy forces are greatest in that regime. The smallest-magnitude Richardson numbers are at pressures farthest from the critical point, suggesting that these conditions should have the lowest buoyancy effects as seen in the velocity maps/ profiles. In the case where buoyancy effects are strong, the lower threshold for turbulence $(R e \approx 200-400)$ would indicate the potential for turbulent effects in this low-Re flow (Jiang et al. 2008c). 
Table 1 Dimensionless numbers for $\mathrm{C}_{2} \mathrm{~F}_{6}$ flowing in a tube

\begin{tabular}{|c|c|c|c|c|c|c|c|c|c|}
\hline \multirow[t]{3}{*}{ Pressure, $P$ (bar) } & \multicolumn{3}{|l|}{$R e_{0}$} & \multicolumn{3}{|l|}{$G r\left(\times 10^{3}\right)$} & \multicolumn{3}{|l|}{$R i$} \\
\hline & \multicolumn{3}{|c|}{ Fluid temperature, $T_{b}\left({ }^{\circ} \mathrm{C}\right)$} & \multicolumn{6}{|c|}{ Wall temperature, $T_{w}\left({ }^{\circ} \mathrm{C}\right)$} \\
\hline & 20 & 21 & 23 & 15 & 21 & 25 & 15 & 21 & 25 \\
\hline $25 \pm 1$ & $95 \pm 5$ & $94 \pm 5$ & $91 \pm 5$ & $-600 \pm 200$ & $-100 \pm 20$ & $90 \pm 20$ & $-80 \pm 20$ & $-12 \pm 2$ & $11 \pm 1$ \\
\hline $29 \pm 1$ & $117 \pm 6$ & $114 \pm 5$ & $110 \pm 5$ & $-11,700 \pm 400$ & $-300 \pm 100$ & $230 \pm 70$ & $-970 \pm 100$ & $-26 \pm 10$ & $21 \pm 5$ \\
\hline $45 \pm 1$ & $86 \pm 1$ & $87 \pm 1$ & $90 \pm 1$ & $-360 \pm 20$ & $-82 \pm 6$ & $91 \pm 7$ & $-45 \pm 2$ & $-10.2 \pm 0.5$ & $10.6 \pm 0.6$ \\
\hline
\end{tabular}

Reynolds numbers $\left(R e_{0}\right)$ are given for the fluid at the magnet entrance, where the bulk temperature $\left(T_{b}\right)$ is in equilibrium with the walls. Grashof $(G r)$ and Richardson $(R i)$ numbers are given for fluid at temperature $T_{b}=23{ }^{\circ} \mathrm{C}$ and at the indicated wall temperatures $\left(T_{w}\right)$. The \pm signs indicate the direction of buoyant forces, and $G r$ is scaled by $10^{3}$ to facilitate comparison. Uncertainties reflect the change within a \pm 1 bar range about the stated pressure to convey their variability, particularly about the critical $P$ and $T$

Propagators are shown in Fig. 7 for the three pressures (rows) and three heat transfer scenarios (columns). These propagators give complementary information to the velocity maps (Fig. 5). Since the profiles are all Poiseuille in the minimal heat transfer case (cf. Fig. 5b), the corresponding propagators (central column, Fig. 7b, e, and h) demonstrate the general features of this case, which are described in (Codd et al. 1999). At short $\Delta$, diffusion dominates, and the propagator is nearly Gaussian, but as $\Delta$ is increased, the expected hat function profile of Poiseuille flow becomes more evident. This is best observed at 45 bar for $\Delta=50 \mathrm{~ms}$ (Fig. 7h), since diffusivity is lower in the supercritical fluid at this higher pressure. Conversely, the diffusive broadening at the lower pressures is greater (Fig. 7b), and this wider Gaussian convolved with the hat function of the velocity distribution broadens and smooths the propagator. At longer $\Delta$, the width of the propagators becomes narrower due to Taylor dispersion, and the known peak at low velocities due to wall reflections emerges (Codd et al. 1999). In terms of the dependence on $\Delta$, all of the general propagator characteristics for Poiseuille flow are observed in the minimal heat transfer scenario.

The propagators for coil temperatures $T_{w}=15$ or $25{ }^{\circ} \mathrm{C}$ are shifted to lower or higher velocities corresponding to heat removal or addition, respectively. For all three pressures, the wall-cooling case (Fig. 7a, d, and g) produces a peak in the curve at low velocities because of the denser, slower-moving fluid near the walls. Near the critical pressure, at $P=29$ bar (Fig. 7d), the relative difference in density near the wall versus the tube center is largest, and there is a more pronounced shift to lower velocities consistent with the downward flowing fluid near the walls (as observed in the corresponding velocity profile, Fig. 5a). The wall-heating case (Fig. 7c, f, and i) produces an increase in the amount of fluid at higher velocities. For $P=25$ bar (Fig. 7c), the propagators look qualitatively similar to the no-heating case because the higher $T_{w}$ maintains the fluid within the supercritical temperature range, and heat transfer effects are therefore not so pronounced as when the $T_{w}$ is below the critical temperature (cf. Fig. 7a). At 29 and 45 bar (Fig. 7f, i), the pronounced high-velocity peak results from the non-parabolic velocity profiles, resulting in more fluid with high velocity.

Figure 8 compares the propagators at the shortest and longest observation times $(\Delta=10$ and $100 \mathrm{~ms})$ in the minimal heat transfer scenario for $P=25,29$, and 45 bar. At the shorter observation time (Fig. 8a), the dynamics are dominated by diffusion, but at the longer time (Fig. 8b) they are dominated by the advective motion. This is evident in that at $10 \mathrm{~ms}$, the curves are near-Gaussian, indicating stochastic Brownian motion, but the $100 \mathrm{~ms}$ curves are hat functions impacted by hydrodynamic dispersion (Codd et al. 1999) indicating Poiseuille advective motion. At the $\Delta=10 \mathrm{~ms}$ observation time, the diffusivity is represented by the width of the Gaussian distributions, while the mean velocity is represented by mean position shift relative to $\mathrm{v}=0 \mathrm{~mm} / \mathrm{s}$. At the 25 and 29 bar pressures, the broader distributions show greater diffusivity compared to the 45 bar case. At the $\Delta=100 \mathrm{~ms}$ observation time, the advective hat function profiles become apparent. Here, peak velocity is shown by the rightmost edge of the hat function, and it can be seen that these agree with the peak velocities from the velocity profiles (cf. Fig. 5b). Notably, the $P=29$ bar propagator has a lower peak velocity due to compressibility. The $\Delta=100 \mathrm{~ms}$ data indicate that hydrodynamic dispersion impacts the nearcritical 29 bar fluid more than the 25 bar high-pressure gas as indicated by the peaking of the distribution near $v=0 \mathrm{~mm} / \mathrm{s}$ due to reflection of fluid near the wall, which generates enhanced sampling of low velocities near the wall (Codd et al. 1999; Rassi et al. 2012). The higher diffusion of the gas and near-critical fluid generate velocity distributions more impacted by hydrodynamic dispersion than the 45 bar supercritical fluid, which indicates slight blunting of the Poiseuille velocity distribution and little impact of diffusion across streamlines at $\delta=100 \mathrm{~ms}$. 
At conditions away from the critical point, minimal time is required to reach steady state. Near the critical point, however, generation of stable velocity distributions takes $\sim 280$ min, and velocity maps (Fig. 9) and propagators (Fig. 10) acquired during this period reveal the progression to steady state. The propagators (Fig. 10) show that the flow started out with an average velocity of $\sim 0.9 \mathrm{~mm} / \mathrm{s}$, and the velocity maps (Fig. 9) show the highest velocities were nearest the walls, falling off to almost zero in the center of the tube. The flow field continued to change until approximately $280 \mathrm{~min}$, with the velocity dropping near the wall and increasing in the center. The velocity maps at 70 and $140 \mathrm{~min}$ are nearly equivalent, and this similarity can also be seen in the corresponding propagators. The propagator that was taken at $175 \mathrm{~min}$ shows commencement of a shift to higher velocities. The final velocity map and propagators reveal that the average velocity is about $2.8 \mathrm{~mm} / \mathrm{s}$ at steady-state conditions. An additional velocity map and propagator taken after the $280 \mathrm{~min}$ threshold during separate runs showed that the final steady-state flow dynamics were repeatable for the given temperature and pressure. The much longer equilibration time near the critical point is presumably due both to fluid compressibility effects and differences in transport properties in this fluid dynamic regime. The compressible, near-critical fluid will require more time to accelerate to its steady-state flow rate than an incompressible fluid. Additionally, the thermal conductivity is known to approach zero at the critical point (Landau and Lifshitz 1959), and the time for the temperature distribution to stabilize across the tube diameter is thus expected to be longer. While temperature profiles were not specifically measured in this study, the velocity maps (Fig. 9) show that the flow field is initially characterized by rapid, buoyancy-driven flow near the walls, but then transitions into a more uniform velocity distribution, suggesting that a temperature gradient has been diminished over the course of the $280 \mathrm{~min}$ equilibration time.

Of interest as well is the transient shift to higher velocities of the propagator at $245 \mathrm{~min}$. The cause of the perturbation is not specifically known, although it might have been a fluctuation in the room temperature. Nonetheless, at later times, the system returned to the same dynamics as observed at $210 \mathrm{~min}$ in all subsequent propagators. This demonstrates the stability of the system under the given thermodynamic conditions, since the same steady-state dynamics are recovered following a perturbation.

\section{Conclusions}

Velocity maps and propagators have been acquired for a supercritical fluid during upward advective flow in a tube. Hexafluoroethane was chosen for the fluid because its critical temperature is below room temperature of the laboratory environment, its critical pressure is relatively easy to maintain inside of the restrictive environment of an MR spectrometer, and the intensity of the ${ }^{19} \mathrm{~F}$ signal is comparable to ${ }^{1} \mathrm{H}$ signal. The flow loop has been designed to accurately control the pressure and flow rate of the fluid for a study of buoyancy effects, and the use of noninvasive MR has shown itself a useful method in revealing the flow dynamics in a near-critical fluid without perturbing the flow. The effect of heat transfer between the fluid and the walls has been explored, and predictions of enhanced sensitivity to wall-cooling/wall-heating when temperature and pressure were near the critical point were confirmed. Propagator measurements indicate the transport dynamics can be tuned using the fluid thermodynamics and heat transfer boundary conditions.

Acknowledgments The authors would like to thank the members of the Magnetic Resonance Laboratory at Montana State University for assistance and support. S.L.C. acknowledges support by the National Science Foundation under CBET Grant 1335534. S.L.C. and J.D.S. acknowledge support, in part, by the Department of Energy under Grant DEFG02-11ER90025. J.M.B. acknowledges support by the Department of Energy under Grant DEFE0000397. Any opinions, findings, and conclusions or recommendations expressed in this material are those of the author(s) and do not necessarily reflect the views of the Department of Energy or the National Science Foundation. Equipment was funded by the National Science Foundation and the M.J. Murdock Charitable trust.

\section{References}

Albert K, Braumann U, Tseng LH, Nicholson G, Bayer E, Spraul M, Hofmann M, Dowle C, Chippendale M (1994) Online coupling of supercritical-fluid chromatography and proton high-field nuclear-magnetic-resonance spectroscopy. Anal Chem 66(19): 3042-3046

Allen LA, Glass TE, Dorn HC (1988) Direct monitoring of supercritical fluids and supercritical chromatographic separations by proton nuclear magnetic-resonance. Anal Chem 60(5): 390-394

Bae YY, Kim HY (2009) Convective heat transfer to $\mathrm{CO}_{2}$ at a supercritical pressure flowing vertically upward in tubes and an annular channel. Exp Therm Fluid Sci 33(2):329-339. doi:10. 1016/j.expthermflusci.2008.10.002

Bae JH, Yoo JY, Choi H (2005) Direct numerical simulation of turbulent supercritical flows with heat transfer. Phys Fluids 17(10). doi:10.1063/1.2047588

Barmatz M, Hahn I, Lipa JA, Duncan RV (2007) Critical phenomena in microgravity: past, present, and future. Rev Mod Phys 79:1-52. doi:10.1103/RevModPhys.79.1

Beysens DA (2005) Near-critical point hydrodynamics and microgravity. In: Kowalewski TA (ed) Mechanics of the 21 st century (Proceedings of the 21st international congress of theoretical and applied mechanics), 15-21 August 2004, Warsaw, Poland. Springer, Netherlands, pp 117-130

Bruch A, Bontemps A, Colasson S (2009) Experimental investigation of heat transfer of supercritical carbon dioxide flowing in a cooled vertical tube. Int J Heat Mass Transf 52(11-12):2589-2598. doi:10.1016/j.ijheatmasstransfer.2008.12.021 
Brunner G (2005) Supercritical fluids: technology and application to food processing. J Food Eng 67(1-2):21-33. doi:10.1016/j. jfoodeng.2004.05.060

Callaghan PT (1991) Principles of nuclear magnetic resonance microscopy. Oxford University Press, New York

Callaghan PT (2011) Translational dynamics and magnetic resonance: principles of pulsed gradient spin echo NMR. Oxford University Press, Oxford

Codd SL, Manz B, Seymour JD, Callaghan PT (1999) Taylor dispersion and molecular displacements in poiseuille flow. Phys Rev E Stat Phys Plasmas Fluids 60(4):R3491-R3494

Dang CB, Hihara E (2004) In-tube cooling heat transfer of supercritical carbon dioxide. Part 2. Comparison of numerical calculation with different turbulence models. Int $\mathrm{J}$ Refrig 27(7):748-760. doi:10.1016/j.ijrefrig.2004.04.017

de Gennes PG (ed) (1975) Phase transition and turbulence: an introduction. In: Proceedings of the NATO advanced study institute on fluctuations, instabilities, and phase transitions. Plenum Press, New York

Duffey RB, Pioro IL (2005) Experimental heat transfer of supercritical carbon dioxide flowing inside channels (survey). Nucl Eng Des 235(8):913-924

Dvoyashkin M, Valiullin R, Karger J (2007a) Supercritical fluids in mesopores-new insight using NMR. Adsorption 13(3-4): 197-200. doi:10.1007/s10450-007-9064-y

Dvoyashkin M, Valiullin R, Karger J, Einicke WD, Glaser R (2007b) Direct assessment of transport properties of supercritical fluids confined to nanopores. J Am Chem Soc 129 (34):10344. doi:10. $1021 / \mathrm{ja} 074101+$

Fard MH (2009) CFD modeling of heat transfer of $\mathrm{CO}_{2}$ at supercritical pressures flowing vertically in porous tubes. Int Commun Heat Mass 37(1):98-102. doi:10.1016/j.icheatmas stransfer.2009.08.004

Fukushima E, Roeder SBW (1981) Experimental pulse NMR: a nuts and bolts approach. Addison-Wesley, Reading, MA

He S, Kim WS, Jackson JD (2008) A computational study of convective heat transfer to carbon dioxide at a pressure just above the critical value. Appl Therm Eng 28(13):1662-1675. doi:10.1016/j.applthermaleng.2007.11.001

Hohenberg PC, Halperin BI (1977) Theory of dynamic critical phenomena. Rev Mod Phys 49(3):435-479

Howell JR, Lee SH (1999) Convective heat transfer in the entrance region of a vertical tube for water near the thermodynamic critical point. Int J Heat Mass Transf 42(7):1177-1187

Hussain R, Pintelon TRR, Mitchell J, Johns ML (2011) Using NMR displacement measurements to probe $\mathrm{CO} 2$ entrapment in porous media. AIChE J 57(7):1700-1709. doi:10.1002/aic. 12401

Jackson JD, Hall WB (ed) (1979) Influences of buoyancy on heat transfer to fluids in vertical tubes under turbulent conditions. In: Turbulent forced convection in channels and bundles. Hemisphere Publishing Corp, New York

Jain PK, Rizwan U (2008) Numerical analysis of supercritical flow instabilities in a natural circulation loop. Nucl Eng Des 238(8):1947-1957. doi:10.1016/j.nucengdes.2007.10.034

Jiang PX, Xu YJ, Lv J, Shi RF, He S, Jackson JD (2004) Experimental investigation of convection heat transfer of $\mathrm{CO}_{2}$ at super-critical pressures in vertical mini-tubes and in porous media. Appl Therm Eng 24(8-9):1255-1270. doi:10.1016/j. applthermaleng.2003.12.024

Jiang PX, Shi RF, Xu YJ, He S, Jackson JD (2006) Experimental investigation of flow resistance and convection heat transfer of $\mathrm{CO}_{2}$ at supercritical pressures in a vertical porous tube. J Supercrit Fluids 38(3):339-346. doi:10.1016/j.supflu.2005.12.004

Jiang PX, Shi RF, Zhao CR, Xu YJ (2008a) Experimental and numerical study of convection heat transfer of $\mathrm{CO}_{2}$ at supercritical pressures in vertical porous tubes. Int J Heat Mass Transf 51(25-26):6283-6293. doi:10.1016/j.ijheatmasstransfer. 2008.05.014

Jiang PX, Zhang Y, Shi RF (2008b) Experimental and numerical investigation of convection heat transfer $\mathrm{Of} \mathrm{CO}_{2}$ at supercritical pressures in a vertical mini-tube. Int $\mathrm{J}$ Heat Mass Transf 51(11-12):3052-3056. doi:10.1016/j.ijheatmasstransfer.2007.09. 008

Jiang PX, Zhang Y, Xu YJ, Shi RF (2008c) Experimental and numerical investigation of convection heat transfer of $\mathrm{CO}_{2}$ at supercritical pressures in a vertical tube at low Reynolds numbers. Int $\mathrm{J}$ Therm Sci 47(8):998-1011. doi:10.1016/j. ijthermalsci.2007.08.003

Jiang PX, Zhao CR, Shi RF, Chen Y, Ambrosini W (2009) Experimental and numerical study of convection heat transfer of $\mathrm{CO}_{2}$ at super-critical pressures during cooling in small vertical tube. Int J Heat Mass Transf 52(21-22):4748-4756. doi:10.1016/ j.ijheatmasstransfer.2009.06.014

Klusman RW (2003) Evaluation of leakage potential from a carbon dioxide EOR/sequestration project. Energy Convers Manag 44(12):1921-1940. doi:10.1016/s0196-8904(02)00226-1

Kuethe DO, Pietrass T, Behr VC (2005) Inert fluorinated gas T-1 calculator. J Magn Reson 177(2):212-220. doi:10.1016/j.jmr. 2005.07.022

Kurganov VA, Kaptil'ny AG (1992) Velocity and enthalpy fields and eddy diffusivities in a heated supercritical fluid flow. Exp Therm Fluid Sci 5:465-478

Kurganov VA, Kaptilnyi AG (1993) Flow structure and turbulent transport of a supercritical pressure fluid in a vertical heated tube under the conditions of mixed convection-experimental-data. Int J Heat Mass Transf 36(13):3383-3392

Landau LD, Lifshitz EM (1959) Fluid mechanics, vol 26. Pergamon Press, London

Lee SH, Howell JR (1996a) Gravitational effects on laminar convection to near-critical water in a vertical tube. $\mathrm{J}$ Thermophys Heat Transf 10(4):627-632

Lee SH, Howell JR (1996b) Laminar forced convection at zero gravity to water near the critical region. J Thermophys Heat Transf 10(3):504-510

Lemmon EW, McLinden MO, Friend DG (2013) Thermophysical properties of fluid systems in NIST chemistry webbook, NIST standard reference database, vol 69. National Institute of Standards and Technology, Gaithersburg, MD 20899. http:// webbook.nist.gov/chemistry/. Accessed 6 May 2013

Liao SM, Zhao TS (2002) An experimental investigation of convection heat transfer to supercritical carbon dioxide in miniature tubes. Int J Heat Mass Trans 45(25):5025-5034

Madani H, Valtz A, Coquelet C, Meniai AH, Richon D (2008) Vaporliquid equilibrium data for the (hexafluoroethane $+1,1,1,2$ tetrafluoroethane) system at temperatures from 263 to $353 \mathrm{~K}$ and pressures up to $4.16 \mathrm{MPa}$. Fluid Phase Equilib 268(1-2):68-72. doi:10.1016/j.fluid.2008.08.011

Maiwald M, Li HP, Schnabel T, Braun K, Hasse H (2007) On-line $\mathrm{H}-1$ NMR spectroscopic investigation of hydrogen bonding in supercritical and near critical $\mathrm{CO}_{2}$-methanol up to $35 \mathrm{MPa}$ and 403 K. J Supercrit Fluids 43:267-275. doi:10.1016/j.supflu. 2007.05 .009

Newling B (2008) Gas flow measurements by NMR. Prog Nucl Magn Reson Spectrosc 52:31-48

Okamoto K, Ota J, Sakurai K, Madarame H (2003) Transient velocity distributions for the supercritical carbon dioxide forced convection heat transfer. J Nucl Sci Technol 40(10):763-767

Okwen RT, Stewart MT, Cunningham JA (2009) Analytical solution for estimating storage efficiency of geologic sequestration of $\mathrm{CO}_{2}$. Int J Greenh Gas Con 4(1):102-107. doi:10.1016/j.ijggc. 2009.11.002 
Onuki A (1998) Nonequilibrium phase transitions in extreme conditions: effects of shear flow and heat flow. J Phys Condens Mat 10(49):11473-11490

Onuki A (2002) Phase transition dynamics. Cambridge University Press, Cambridge

Onuki A, Kawasaki K (1978) Fluctuations in non-equilibrium steady states with laminar shear-flow-classical fluids near the criticalpoint. Sup Prog Theor Phys 64:436-441

Orr FM, Taber JJ (1984) Use of carbon-dioxide in enhanced oilrecovery. Science 224(4649):563-569

Parker ME, Meyer JP, Meadows SR (2009) Carbon dioxide enhanced oil recovery injection technologies. In: Gale J, Herzog $\mathrm{H}$, Braitsch J (eds) Greenhouse gas control technologies 9 (Energy Procedia), vol 1, pp 3141-3148

Pioro IL, Khartabil HF, Duffey RB (2004) Heat transfer to supercritical fluids flowing in channels-empirical correlations (survey). Nucl Eng Des 230(1-3):69-91

Rassi EM, Codd SL, Seymour JD (2012) MR measurement of critical phase transition dynamics and supercritical fluid dynamics in capillary and porous media flow. J Magn Reson 214:309-314. doi:10.1016/j.jmr.2011.09.045

Ravagnani A, Ligero EL, Suslick SB (2009) $\mathrm{CO}_{2}$ sequestration through enhanced oil recovery in a mature oil field. J Petrol Sci Eng 65:129-138

Saikawa K, Kijima J, Uematsu M, Watanabe K (1979) Determination of the critical-temperature and density of hexafluoroethane. J Chem Eng Data 24(3):165-167
Stanley HE (1971) Introduction to phase transitions and critical phenomena. Oxford University Press, New York

Stejskal EO, Tanner JE (1965) Spin diffusion measurements: spin echoes in the presence of a time-dependent field gradient. J Chem Phys 42:288

Suekane T, Furukawa N, Tsushima S, Hirai S, Kiyota M (2009) Application of MRI in the measurement of two-phase flow of supercritical $\mathrm{CO}_{2}$ and water in porous rocks. J Porous Media 12(2): $143-154$

Tanaka H, Tsuge A, Hirata M, Nishiwak N (1973) Effects of buoyancy and of acceleration owing to thermal-expansion on forced turbulent convection in vertical circular tubes-criteria of effects, velocity and temperature profiles, and reverse transition from turbulent to laminar-flow. Int J Heat Mass Transf 16(6):1267-1288

Van der Meer LGH (1995) The $\mathrm{CO}_{2}$ storage efficiency of aquifers. Energy Convers Manag 36(6-9):513-518

Yonker CR, Linehan JC (2005) The use of supercritical fluids as solvents for NMR spectroscopy. Prog Nucl Magn Reson Spectrosc 47(1-2):95-109. doi:10.1016/j.pnmrs.2005.08.002

Zappoli B (2003) Near-critical fluid hydrodynamics. CR Mech 331(10):713-726. doi:10.1016/j.crme.2003.05.001

Zappoli B, Amiroudine S, Gauthier S (1999) Rayleigh-Taylor-like instability in near-critical pure fluids. Int $\mathbf{J}$ Thermophys 20(1):257-265

Zhou N, Krishnan A (1995) Laminar and turbulent heat transfer in flow of supercritical $\mathrm{CO}_{2}$. In: 1995 national heat transfer conference, Portland, OR, 1995. ASME, pp 53-63 